\title{
Effect of Light on Carbohydrates and Hydrosoluble Vitamins of Lentils during Soaking
}

\author{
JUANA FRIAS, MARIN PRODANOV, ISABEL SIERRA, and CONCEPCION VIDAL-VALVERDE*
}

Instituto de Fermentaciones Industriales (CSIC), Juan de la Cierva 3, 28006 Madrid, Spain

(MS\# 94-121: Received 8 June 1994/Accepted 25 October 1994)

\section{ABSTRACT}

Lentils have been soaked with and without light to investigate the effect of the light on carbohydrates and soluble vitamins during the soaking process. Soaking significantly decreased the $\alpha$-galactoside content of lentils (3.2\% to $1.2 \%$ or $1.0 \%$ ). Glucose (not present in raw seeds) and fructose increased with soaking with light. Raffinose was completely eliminated in presence of light but was still present after soaking in the dark $(0.15 \%)$. The overall results confirm previous findings, but the soaking process cannot be explained simply as a result of sugars leaching into the soaking media. On the contrary, some metabolic processes must be inferred, and light plays a certain role in the process. The NDF, ADF, cellulose, hemicellulose, and lignin contents were not significantly modified by soaking with or without light. Total and digestible starch significantly increased after soaking (52\% to $58 \%$ and $45 \%$ to $52 \%$, respectively), but an influence of light was not detected. The ratio of digestible starch to total starch improved during soaking, an indication that digestibility could be enhanced after this process. No effect of light during the soaking process has been observed on the vitamin content of processed lentils. Thiamin and niacin decreased significantly with soaking as a result of leaching into the water, but riboflavin increased significantly. Again, this result may imply the onset of metabolic processes during soaking, although no light effect has been observed.

Key words: Lentils, soaking, light effect, carbohydrates, hydrosoluble vitamins

Lentil seeds are a good source of reasonable quantities of protein, complex carbohydrates, vitamins, and certain minerals, and their global contribution to diets is appreciable (2). Dry legumes, however, contain several undesirable attributes such as antinutritional compounds which have to be removed/eliminated for effective utilization of lentils. Most of them are heat labile and can be removed by heat treatments. Alpha-galactosides (raffinose, ciceritol, stachyose, verbascose), one of the main reasons people limit the consumption of pulses $(5,8,14)$, are stable to high temperature and are not completely removed by cooking.
Soaking usually is a part of legume-processing methods, because it facilitates quicker cooking. Certain water-soluble components, nutritionally important minerals, and vitamins may be lost in the soaking solution, if discarded, along with undesirable components such as flatulence-causing oligosaccharides. It has been shown that $9 \mathrm{~h}$ of soaking of lentils substantially modifies the $\alpha$-galactoside content of the seeds (22). The fiber content was also appreciably modified by this process $(20)$. Changes in the soluble carbohydrate content as a result of soaking have usually been explained as a consequence of these sugars being leached into the soaking liquid $(9,10,11)$. However the detailed analysis of the soaking media carried out by Vidal-Valverde, Frias, and Valverde (22) unequivocally showed that leaching scarcely contributed to the lowering of the $\alpha$-galactoside content of the raw seeds, since some metabolic reactions also take place. In this context, it was considered of interest to study the effects of soaking in the presence and absence of light on the soluble carbohydrates (monosaccharides, disaccharides, and $\alpha$-galactoside oligosaccharides), total and in vitro digestible starch, dietary fiber components, and three water-soluble vitamins (thiamin, riboflavin, and niacin) in lentils, which is the aim of this work.

\section{MATERIALS AND METHODS}

\section{Preparation of the sample}

Lentils (Lens culinaris var. vulgaris) were purchased at a local market. For the soaking treatments two different batches were used. Lentil seeds were placed in a glass container and soaked in distilled water $\left(1: 3 \mathrm{w} / \mathrm{v}\right.$ seed:water ratio) at $22^{\circ} \mathrm{C}$ for $9 \mathrm{~h}$ to obtain maximum seed weight and hydration (I). Soaking experiments performed with light exposure were carried out leaving the seeds in the daylight. The other lentil batch was protected from light. Then the soaked seeds were strained to drain off the water, freeze-dried, ground, and passed through an $0.18 \mathrm{~mm}$ sieve before analysis. Both experiments were performed in duplicate. 
Determination of soluble carbohydrates

Extraction and quantification of mono- and disaccharides and alpha-galactosides was carried out as described by VidalValverde, Frias, and Valverde (22).

\section{Starch determination}

Total starch was determined using a procedure based on total enzyme digestion of starch to glucose $(3,6)$. Digestible starch was determined following the procedure described by $\mathbf{L i}$, Schuhmann, and Wolf (12) after 30 min of enzymic incubation. Glucose content obtained after enzymic starch hydrolysis was measured by the method of Dahlqvist (7).

\section{Dietary fiber determination}

The methods of Van Soest and Wine $(17,18)$ and McQueen and Nicholson (13) were used to determine the content of neutral detergent fiber (NDF), acid detergent fiber (ADF), cellulose, hemicellulose, and lignin. In accordance with those researchers a preliminary overnight incubation with bacterial $\alpha$-amylase was employed.

\section{Thiamin and riboflavin determination}

A single extraction procedure for both thiamin and riboflavin was carried out as in a previous paper (21). Thiamin was quantified by high-performance liquid chromatography (HPLC) using post-column derivatization and fluorescence detection as in Wimalasiri and Wills (25). The mobile phase used was methanol/water/acetic acid (31/68.5/0.5 v/v) and $5 \mathrm{mM}$ sodium hexanesulphonate, and the flow rate was $1.5 \mathrm{~mL} / \mathrm{min}$. The column temperature was $35^{\circ} \mathrm{C}$. Riboflavin was determined by HPLC with fluorescence detection as in (21).

\section{Available niacin determination}

Analyses of available niacin were carried out by HPLC with absorbance detection as in Vidal-Valverde and Reche (23), but some changes have been introduced. The column temperature was $37^{\circ} \mathrm{C}$; and two different mobile phases at a flow rate of 1.4 $\mathrm{ml} / \mathrm{min}$ were used: mobile phase $\mathrm{A}(\mathrm{pH} \mathrm{4.72)}$, methanol/0.01 $\mathrm{M}$ sodium acetate buffer $(\mathrm{pH} 4.66)(1 / 9 \mathrm{v} / \mathrm{v})$ and $5 \mathrm{mM}$ tetrabutylammonium bromide; and mobile phase $\mathbf{B}$, methanol/ $0.01 \mathrm{M}$ sodium acetate buffer $(\mathrm{pH} 4.66)(9 / 1 \mathrm{v} / \mathrm{v})$ and $5 \mathrm{mM}$ tetrabutylammonium bromide. After acquiring the niacin peak by isocratic elution with mobile phase $A$, mobile phase $B$ was used to remove impurities from the chromatographic column (gradient $7 \mathrm{~min}$ and isocratic elution $8 \mathrm{~min}$ ). Mobile phase $\mathrm{A}$ was passed through the column again (gradient $4 \mathrm{~min}$ and isocratic elution 4 $\mathrm{min}$ ) before proceeding to the next analysis. The total analysis was performed in $35 \mathrm{~min}$.

\section{Statistical methods}

Multifactor analysis of variance was applied to the data using Statgraphic Statistical Graphics System 5.0 software.

\section{RESULTS AND DISCUSSION}

The content for fructose, glucose, sucrose, oligosaccharide $\alpha$-galactosides, and total soluble sugars in raw and soaked lentils in me presence and absence of light are presented in Table 1. Fructose, sucrose, raffinose, ciceritol, and stachyose were observed in raw lentils. The identity of these carbohydrates was previously established by onedimensional and two-dimensional thin-layer chromatography (TLC) using known standards (24). Although TLC analysis indicated that one of the oligosaccharides was manninotriose, a carbohydrate obtained by enzymic hydrolysis of stachyose by $\beta$-fructosidase (26), the HPLC analysis clearly rejected this finding and confirmed the presence of ciceritol in lentil samples (Fig. 1), as has been previously reported $(4,15)$.

The soaking treatment decreased the total soluble sugar content, from $4.5 \%$ in the unsoaked material to $2.5 \%$ in the soaked lentils, when the procedure was carried out with light. A more pronounced decrease (from $4.5 \%$ to $1.8 \%$ ) was observed when the treatment was performed in the dark. The content of alpha-galactosides dropped from $3.2 \%$ to $1.2 \%$ when the soaking in water was carried out with light, and raffinose was completely eliminated. These results agree well with those previously reported by VidalValverde, Frias, and Valverde (22), who found a 45-100\% reduction of individual $\alpha$-galactosides after soaking. Sucrose also underwent a significant loss (25\%). However, glucose was found in lentils after soaking in water with light, despite it not being detected in raw lentils, and fructose slightly increased after soaking, regardless of the light conditions. When the soaking treatment was carried out without light, raffinose was found in quite high quantities $(0.15 \%)$. A large amount of other soluble sugars was removed during this hydration procedure: we found losses of $44 \%$ for sucrose, $69 \%$ for ciceritol, and $74 \%$ for stachyose. These data indicate that the soaking process, in the absence of light, brought about higher losses. These observed reductions were due not only to leaching effects $(8,10,11)$, but also to metabolic processes $(19,22)$, which could be affected by the light exposure.

Table 2 shows the content of NDF, ADF, cellulose, hemicellulose, and lignin in raw and soaked lentil seeds with and without light. There was no significant influence of light on the effect of soaking in the content of dietary fiber components. The results obtained agree well with previous data (20).

TABLE 1. Changes in soluble carbohydrate content of lentils after soaking in water with and without light.

\begin{tabular}{lcccccccc}
\hline Treatment & Fructose & Glucose & Sucrose & Raffinose & Ciceritol & Stachyose & $\begin{array}{c}\text { Alpha- } \\
\text { galactosides }\end{array}$ & $\begin{array}{c}\text { Total Soluble } \\
\text { Sugars }\end{array}$ \\
\hline $\begin{array}{l}\text { Raw lentils } \\
\text { Soaked lentils }\end{array}$ & $0.09 \pm 0.01^{\mathrm{a}}$ & ND & $1.26 \pm 0.06^{\mathrm{a}}$ & $0.22 \pm 0.03^{\mathrm{a}}$ & $1.01 \pm 0.03^{\mathrm{a}}$ & $1.96 \pm 0.16^{\mathrm{a}}$ & $3.19^{\mathrm{a}}$ & $4.54^{\mathrm{a}}$ \\
With light & $0.11 \pm 0.02^{\mathrm{h}}$ & $0.25 \pm 0.02^{\mathrm{h}}$ & $0.93 \pm 0.07^{\mathrm{h}}$ & $\mathrm{ND}$ & $0.54 \pm 0.04^{\mathrm{b}}$ & $0.66 \pm 0.07^{\mathrm{h}}$ & $1.20^{\mathrm{h}}$ & $2.49^{\mathrm{h}}$ \\
Without light & $0.11 \pm 0.01^{\mathrm{h}}$ & $\mathrm{ND}$ & $0.69 \pm 0.02^{\mathrm{c}}$ & $0.15 \pm 0.04^{\mathrm{h}}$ & $0.31 \pm 0.04^{\mathrm{c}}$ & $0.51 \pm 0.07^{\mathrm{c}}$ & $0.97^{\mathrm{b}}$ & $1.77^{\mathrm{c}}$ \\
\hline
\end{tabular}

Note: Values (g/100 dry weight) are the means of four determinations of each batch \pm standard deviation. Different superscripts in the same column indicate significant differences $(P \leq 0.05)$. 

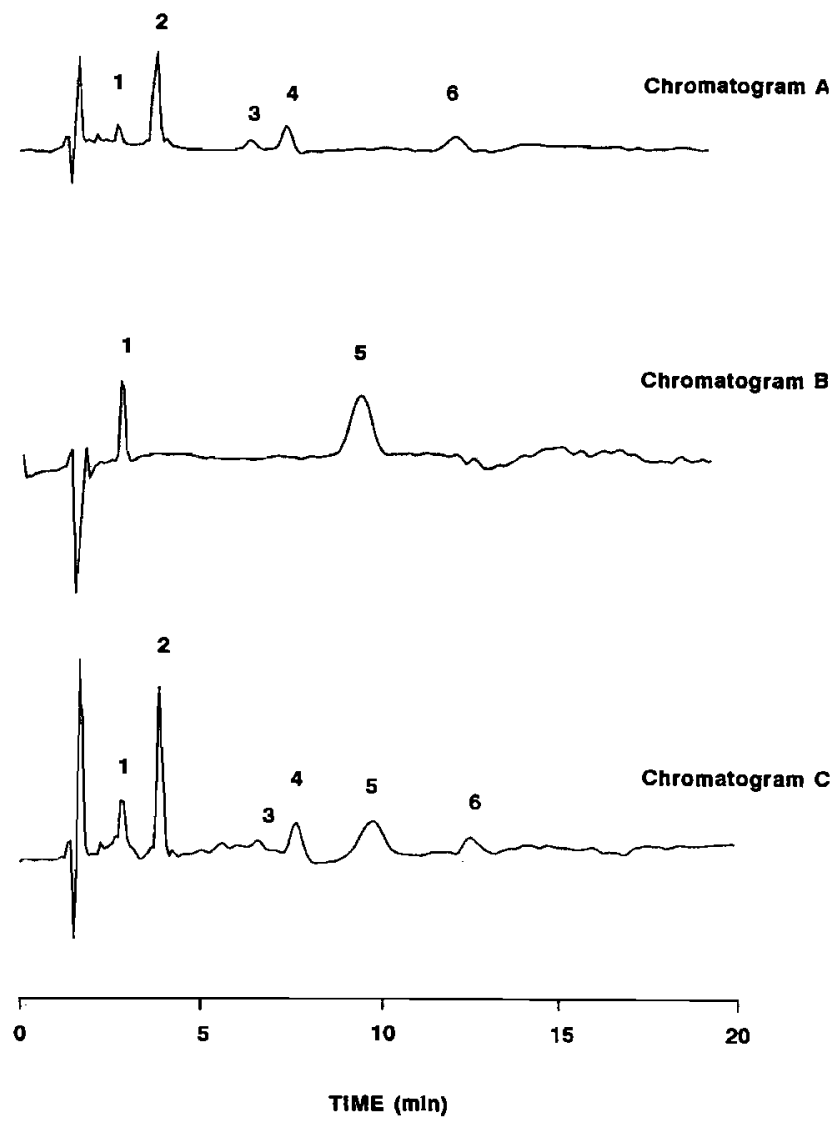

Figure 1. HPLC chromatograms obtained from raw lentil extract (A), from hydrolysis of stachyose using $\beta$-fructosidase $(B)$, and from a mixture of both solutions $(C)$. 1, fructose; 2 , sucrose; 3 , raffinose; 4, ciceritol; 5, manninotriose; 6, stachyose; y axes (absorbance).

The total starch content increased after soaking in water (52\% in dry lentil seeds versus $58 \%$ in soaked seeds), and also the in vitro digestible starch (45\% to $52 \%$ ), but we did not find significant differences between the results obtained soaking lentils in the presence or absence of light (Table 3). On the other hand the ratio of in vitro digestible starch to total starch (rate of starch digestibility) was higher in the soaked lentils than in the unsoaked lentils. The in vitro starch digestibility after soaking may be enhanced by weakening of the starch granule and thus improving its digestibility (16), and light during soaking did not apparently affect it.

The results obtained for vitamins of raw and soaked lentils in the presence or absence of light are summa- rized in Table 4. After soaking, thiamin and niacin content decreased significantly $(\mathrm{P} \leq 0.05)$, possibly due to leaching effects. On the contrary, riboflavin increased in soaked seeds compared with untreated lentils. This effect could be explained by considering that during the soaking treatment some metabolic processes take place (22), as has been previously reported in fermented lentils $(21)$. No difference in the vitamin content of soaked lentils was observed as a result of the presence or absence of light $(P \leq 0.05)$. Contrary to what we had expected there were no apparent losses of riboflavin, the most light-sensitive vitamin. We have found no information about the influence of light during the soaking process on the hydrosoluble vitamins in legumes.

TABLE 3. Changes in total and digestible starch content of lentils after soaking in water with and without light.

\begin{tabular}{lccc}
\hline Treatment & Total Starch & $\begin{array}{c}\text { Digestible } \\
\text { Starch }\end{array}$ & $\begin{array}{c}\text { Digestible Starch/ } \\
\text { Total Starch (\%) }\end{array}$ \\
\hline Raw lentils & $52.27 \pm 0.69^{\mathrm{a}}$ & $44.82 \pm 0.53^{\mathrm{a}}$ & $86^{\mathrm{a}}$ \\
& & & \\
Soaked lentils & & & \\
$\begin{array}{l}\text { With light } \\
\text { Without light }\end{array}$ & $57.84 \pm 0.75^{\mathrm{h}}$ & $52.28 \pm 0.57^{\mathrm{h}}$ & $90^{\mathrm{h}}$ \\
& $57.1 .15^{\mathrm{b}}$ & $51.82 \pm 0.63^{\mathrm{h}}$ & $90^{\mathrm{b}}$ \\
\hline
\end{tabular}

Note: Values ( $g / 100$ dry weight) are the means of four determinations of each batch \pm standard deviation. Different superscripts in the same column indicate significant differences $(P \leq 0.05)$.

TABLE 4. Changes in thiamin, riboflavin, and available niacin content of lentils after soaking in water with and without light.

\begin{tabular}{lccc}
\hline Treatment & Thiamin & Riboflavin & Available Niacin \\
\hline Raw lentils & $0.49 \pm 0.01^{\mathrm{a}}$ & $0.03 \pm 0.004^{\mathrm{a}}$ & $1.24 \pm 0.09^{\mathrm{a}}$ \\
& & & \\
Soaked lentils & & & \\
With light & $0.44 \pm 0.02^{\mathrm{b}}$ & $0.05 \pm 0.01^{\mathrm{b}}$ & $0.45 \pm 0.05^{\mathrm{b}}$ \\
Without light & $0.43 \pm 0.02^{\mathrm{h}}$ & $0.05 \pm 0.01^{\mathrm{h}}$ & $0.48 \pm 0.01^{\mathrm{b}}$ \\
\hline
\end{tabular}

Note: Values ( $\mathrm{g} / 100 \mathrm{dry}$ weight) are the means of four determinations of each batch \pm standard deviation. Different superscripts in the same column indicate signiticant differences $(\mathrm{P} \leq 0.05)$.

TABLE 2. Changes in content of dietary fiber components of lentils after soaking in water with and without light.

\begin{tabular}{lcccc}
\hline Treatment & NDF & ADF & Cellulose & Hemicellulose \\
\hline Raw lentils & $21.27 \pm 0.25^{\mathrm{a}}$ & $6.75 \pm 0.07^{\mathrm{a}}$ & $5.33 \pm 0.07^{\mathrm{a}}$ & $14.49 \pm 0.26^{\mathrm{a}}$ \\
& & & & \\
Soaked lentils & & & & \\
With light & $20.98 \pm 0.51^{\mathrm{a}}$ & $7.86 \pm 0.43^{\mathrm{h}}$ & $6.40 \pm 0.57^{\mathrm{h}}$ & $13.11 \pm 0.83^{\mathrm{a}}$ \\
Without light & $21.36 \pm 0.36^{\mathrm{a}}$ & $8.27 \pm 0.51^{\mathrm{h}}$ & $6.75 \pm 0.56^{\mathrm{h}}$ & $13.10 \pm 0.74^{\mathrm{a}}$ \\
\hline
\end{tabular}

Note: Values $(\mathrm{g} / 100 \mathrm{~g}$ dry weight) are the means of four determinations of each batch \pm standard deviation. NDF $=$ neutral detergent fiber, ADF $=$ acid detergent fiber. Different superscripts in the same column indicate significant differences $(\mathrm{P} \leq 0.05)$. 


\section{ACKNOWLEDGMENTS}

This study was supported by the Spanish Comision Interministerial de Ciencia y Tecnologia (CICYT) AL1-91-1092-C02-01.

\section{REFERENCES}

1. Abou-Samaha, O. R., A. R. El-Mahdy, and Y. G. Moharram. 1985. Effect of soaking on the quality of lentil seeds. Z. Lebensm. Unters. Forsch. 180:485-490.

2. Adsule, R. N., S. S. Kadam, and H. K. Leung. 1989. Lentil. 131-153. In D. K Salunkhe and S. S. Kadam (eds.). CRC Handbook of World Food Legumes: Nutritional Chemistry, Processing Technology, and Utilization. vol Il. CRC Press. Inc., Boca Raton, FL.

3. Bakhsh, A., D. A. Jones, C. L. Hedley, and N. Lambert. 1991. Genetic variation for seed storage product composition in lentils (Lens culinaris). Aspects Appl. Biol. 27:279-281.

4. Bernabe, M., R. G. Fenwick, J. Frias, J. Jimenez-Barbero, K. Price, S. Valverde, and C. Vidal-Valverde. 1993. Determination, by NMR spectroscopy, of the structure of ciceritol, a pseudotrisaccharide isolated from lentils. J. Agric. Food Chem. 41:870-872.

5. Calloway, D. H., C. A. Hickey, and E. L. Murphy. 1971. Reduction of intestinal gas-forming properties of legumes by traditional and experimental food processing methods. J. Food Sci. 36:251-255.

6. Carpita, N. C., and J. Kabanus. 1987. Extraction of starch by dimethyl sulfoxide and quantification by enzymatic assay. Anal. Biochem. 161:132-139.

7. Dahlqvist, A. 1964. Method for assay of intestinal disaccharidases. Anal. Biochem. 7:18-27.

8. Iyer, V., D. K. Salunkhe, S. K. Sathe, and L. B. Rockland. 1980. Quick-cooking beans (Phaseolus vulgaris L.). II. Phytates, oligosaccharides, and antienzymes. Qual. Plant. Foods Hum. Nutr. 30:45-52.

9. Kataria, A., B. N. Chauhan, and D. Punia. 1990. Effect of domestic processing and cooking methods on the content of carbohydrates of amphidiploids (black gram $x$ mung bean). Food Chem. 36:63-72.

10. Jood, S., B. M. Chauhan, and A. C. Kapoor. 1988. Contents and digestibility of carbohydrates of chickpea and blackgram as affected by domestic processing and cooking. Food Chem. 30:113127.

11. Jood, S., U. Mehta, and R. Singh. 1986. Effect of processing on available carbohydrates in legumes. J. Agric. Food Chem. 36:417420.
12. Li, B. W., P. J. Shuhmann, and W. R. Wolf. 1985. Chromatographic determination of sugars and starch in a diet composite reference material. J. Agric. Food Chem. 33:531-536.

13. McQueen, R. A., and J. W. G. Nicholson. 1979. Modification of the neutral detergent fiber procedure for cereal and vegetables by using $\alpha$-amylase. J. Assoc. Off. Anal. Chem. 62:676-680.

14. Price, K. R., J. Lewis, G. M. Wyatt, and G. R. Fenwick. 1988. Flatulence - causes, relation to diet and remedies. Die Nahrung 32:609-626.

15. Quemener, B., and J. M. Brillouet. 1983. Ciceritol, a pinitol digalactoside from seeds of chick-pea, lentil and white lupines. Phytochemistry 22:1745-1751.

16. Snow, P., and K. O'Dea. 1981. Factors affecting the rate of starch hydrolysis in food. Am. J. Clin. Nutr. 34:2721-2727.

17. Van Soest, J. P., and R. H. Wine. 1967. Use of detergents in the analysis of fibrous feeds. Determination of plant cell-wall constituents. J. Assoc. Off. Anal. Chem. 50:50-55.

18. Van Soest, J. P., and R. H. Wine. 1968. Determination of lignin and cellulose in acid detergent fiber with permanganate. J. Assoc. Off. Anal. Chem. 51:780-784.

19. Vidal-Valverde, C., and J. Frias. 1992. Changes in carbohydrates during germination of lentils. Z. Lebensm. Unters. Forsch. 194:461464.

20. Vidal-Valverde, C., J. Frias, and R. Esteban. 1992. Dietary fiber in processed lentils. J. Food Sci. 57:1161-1163.

21. Vidal-Valvende, C., J. Frias, M. Prodanov, J. Tabera, R. Ruiz, and J. Bacon. 1993. Effect of natural fermentation on carbohydrates, riboflavin and trypsin inhibitor activity of lentils. Z. Lebensm. Unters. Forsch. 197:449 452.

22. Vidal-Valverde, C., J. Frias, and S. Valverde. 1992. Effect of processing on the soluble carbohydrate content of lentils. J. Food Protect. 55:301-304.

23. Vidal-Valverde, C., and A. Reche. 1991. Determination of available niacin in legumes and meat by high-performance liquid chromatography. J. Agric. Food Chem. 39:116-121.

24. Vidal-Valverde, C., and E. Rojas-Hidalgo. 1976. A chromatographicpolarimetric method for quantitative determination of some sugars. An. Quim. 72:275-279.

25. Wimalasiri, P., and R. B. H. Wills. 1985. Simultaneous analysis of thiamin and riboflavin in foods by high performance liquid chromatography. J. Chromatogr. 318:412-416.

26. Wright, A. W., and P. J. Van Niekerk. 1983. A sensitive and selective method for the determination of reducing sugars and sucrose in food and plant material by high performance liquid chromatography. Food Chem. $10: 211-224$. 